24 Von Berchtold M. Memoirs of Mozart's sister (1800). In: Deutsch OE. Mozart, a documentary biography. Stanford: Stanford University Press, 1965:493-4.

25 Lange J. Reminiscences (1808). In: Deutsch OE. Mozart, a documentary biography. Stanford: Stanford University Press, 1965:503.

26 Sacks O. Dinner address. In: Walker DE, Mellberg MI. Second international scientific symposium on Tourette syndrome. New York: Tourette Syndrom Association, 199

27 Zametkin AJ, Nordahl TE, Gross M, King AC, Semple WE, Rumsey J, et al.
Cerebral glucose metabolism in adults with hyperactivity of childhood onset. $N$ Engl f Med 1990;323:1361-6.

28 Comings DE, Comings BG, Muhleman D, Dietz G, Shahbahrami B, Tast D, et al. The dopamine $\mathrm{D}_{2}$ receptor locus as a modifying gene in neuropsychiatric discorders. FAMA 1991;266:1793-800.

29 Mahler MS, Rangell L. A psychosomatic study of maladie des tics (Gilles de la Tourette's disease). Psychiutr $Q$ 1943;17:579-603.

30 Murray TJ. Dr Samuel Johnson's movement disorder. BMF 1979;i:1610-4.

\title{
Music making
}

\section{R L Kneebone}

Last year I built a harpsichord from a kit. The idea of doing this had been fluttering about at the back of my mind for many years, but only when I decided to take the plunge did I really begin to learn what it would involve.

First I went to the early music exhibition in London. This takes place every two years, and all manner of curious people congregate there. Before I went I had thought that superspecialisation was the peculiar province of doctors. I was quite wrong. The early music world's answer to the neonatal neuroendocrinologist is someone whose life is spent designing the complex tools which instrument makers use to carve the scrolls of baroque viols.

The exhibition was full of instruments that I had only ever read about - and some I had never even heard of. There were hurdy-gurdies, serpents, crumhorns, shawms, theorbos, and all sorts of even rarer breeds. I even had a go on a quint bass curtal.

Of the several makers of harpsichord kits, by far the best was John Storrs of Chichester. His kits are based closely on traditional designs and use mainly traditional materials. He uses computerised equipment, though, to make the really tricky parts where a novice could easily go dreadfully wrong. I ordered my kit from him.

\section{Trowbridge, Wiltshire BA14 7JG R L Kneebone, general} practitioner
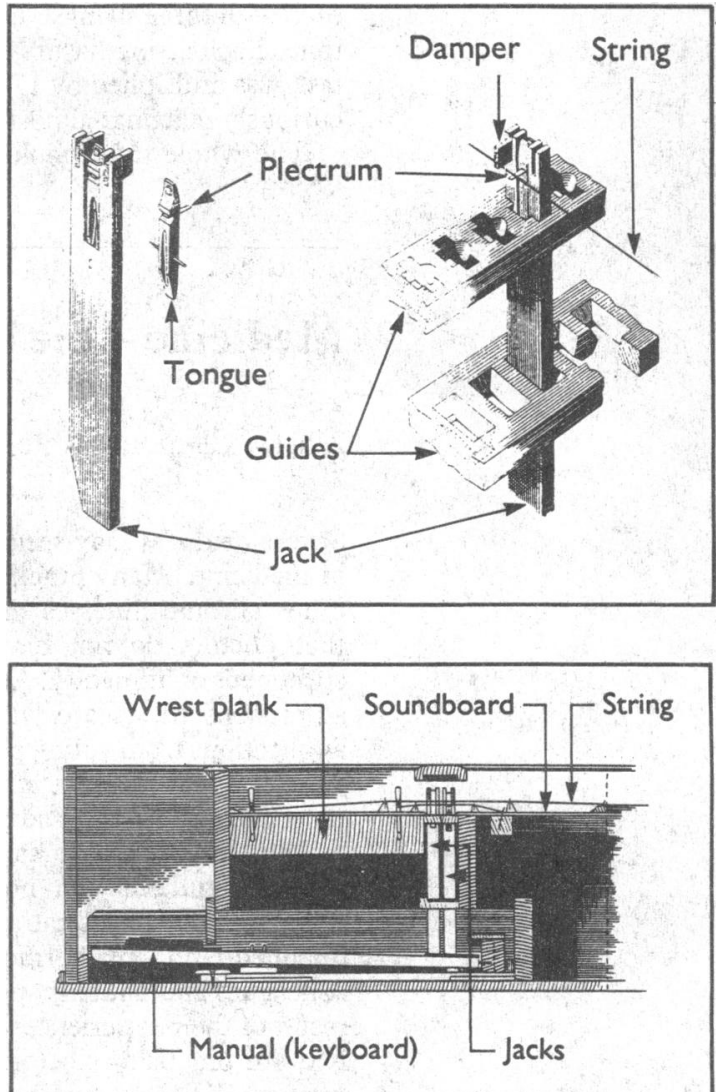

Harpsichord action: (top) the plectrum fits into the tongue, which fit into the jack, which is held in position by guides and rests on the key; (bottom) the cross section shows how the string is held by tuning pins fitted into the wrest plank and runs over the soundboard. When the key is depressed the plectrum rises and plucks the string; when the key is released the damper descends to stop the string vibrating. A two manual harpsichord is shown

A couple of months later my kit arrived. I took a fortnight's "harpsichord leave" from the practice and began. The number of bits and pieces was formidable, but the instructions in the booklet seemed very clear. I started at once-and nearly fell at the first fence.

As instructed, I started with a dummy run and fitted the bits together without glue. That seemed fine, except that I found I had put the wrest plank in back to front. This is like building a car and putting the pedals on the ceiling and the sunroof under the seat.

I took my kit to bits again, covered the parts with glue and cramped it all together. This time I made quite sure that the wrest plank was not back to frontbut put it in upside down instead. I just managed to get it to come unstuck before it did the same to me.

The mechanism of the harpsichord seems absurdly simple, but it works amazingly well. On the distal end of each key are the jacks. Each has a little wooden $z$ tongue that pivots sideways; this tongue holds the plectrum. This plectrum plucks the string on its way up and swivels out of its way as it comes back. Because 
the mechanism is so light it is very responsive, allowing extremely rapid trills and ornaments to be played. The plectra are made of special plastic. This is one of the maker's few concessions to the twentieth century, since the more traditional vulture quills are a problem to supply and replace, especially here in Wiltshire.

The most time consuming part of the construction process was the voicing. Each plectrum has to be cut to exactly the right length and thickness so that the notes all sound balanced. I spent many laborious hours with a bright light and a scalpel, improving my command of my native tongue each time I scraped a fraction of a millimetre too far and had to start all over again with a new plectrum.

Mine is a single manual harpsichord. It has $\mathbf{5 8}$ keys, each with three strings. This provides great richness of tone. Each string has its own jack, however, so every task was multiplied by 174 . This repetitive work had a curiously relaxing, almost hypnotic effect.

The whole thing took about six months to finish.
Since then I have been learning to play it. I spend hours tuning it, too, for it is morbidly sensitive to changes in the weather. For the first 20 minutes or so after a tuning it sounds glorious. It then undergoes a sort of malignant change, especially if the air is damp, and gradually comes to sound like a honky-tonk harpsichord. The frustrations of assembling the kit have now paled into insignificance beside the problems of getting to grips with harpsichord technique. You have no control over how loud a note is, for either the jack plucks a string or it doesn't. But you do have complete control over the timing of each note, and it is this precision that provides the subtlety of playing.

Making the harpsichord was tremendous fun and very satisfying, for I achieved a definite aim. But the real challenge now lies in learning to play it.

The next Early Music Exhibition will be held in London in late October or early November 1993 . John Storrs kits are available from North Mundham, Chichester, West Sussex PO20 6JU (tel 0243 776263).

\title{
Medicine - the hearing profession?
}

\author{
Mark J Clemons, Kate R Clemons, Rod Skinner
}

Severe deafness may seem incompatible with a career in medicine. Many practising doctors, however, have other chronic illnesses or disabilities, ${ }^{1}$ which shows that doctors do not have to be physically perfect specimens of humanity. Although some medical school admissions tutors are willing to look favourably on applications from young people with disabilities of this nature, such attitudes may not be universal among those who give careers advice.

This article aims to suggest that hearing impaired medical students can not only survive the undergraduate course but can also function normally once qualified and, furthermore, may be able to offer colleagues and patients special attitudes and skills as a result of their experiences in life. Two of us, MJC and $\mathrm{RS}$, are practising doctors who have been deaf from infancy; KRC, a medical student studying the education of the hearing impaired child and adult, helped to clarify many of the views expressed in this paper.

\section{Using the "good" ear}

I (MJC) have been hearing impaired since infancy, my loss being moderate at low frequencies but profound at higher frequencies. A hearing aid in my less severely affected ear, combined with a degree of speech reading and recognition of non-verbal cues, enables me to maximise my residual hearing. I was brought up in an "oralist" way, living as a hearing person in a hearing world. I learnt to cope in a mainstream school by sitting at the front, asking the teacher to face towards me, and interrupting if I missed anything. I knew I wanted to be a doctor from an early age and was encouraged by family and teachers. I considered myself a successful pupil by any standard, deaf or not, and did not mention my hearing loss on my university application form.

I encountered many difficulties throughout my six years as a student but did not allow them to discourage me. The preclinical course had many problems, especially in lectures. The combination of background noise from 130 fellow students, the continual pacing of many lecturers, and the intermittent obliteration of visual clues by darkness created considerable difficulties. My colleagues were able to "focus" their hearing onto the lecturer, but this was almost impossible for someone wearing a hearing aid since all of the peripheral sounds were amplified equally, allowing little voluntary selection. I was able to compensate only by concentrated reading around the subject.

In the clinical course, most of the difficulties I encountered were related more to other people's lack of understanding of deafness than to my hearing impairment itself. On my first day on the wards I was humiliated by the consultant, who did not understand that I had failed to hear his questions. There were eight people, in descending order of rank, between us, and the clatter of bedpans was amplified out of all proportion as they were closer to my hearing aid than the consultant was. Even though I had no idea that he was talking to me, I was branded as inattentive. After that I was always to be found at the front of the group on ward rounds. However, I still have to endure the sight of "professionals" shouting at deaf patients and treating them as though they lacked intelligence. This attitude is degrading to the patient and, I feel, to the doctors themselves.

I do not think that my clinical skills have suffered greatly from my hearing impairment. I use a specially amplified stethoscope and have not been aware of missing many auscultatory signs heard by my peers. In the ward I sit by the patients' beds with my "good" ear towards them to maximise my hearing.

I have received much support from my peers and many qualified colleagues, who have shown genuine interest in my problems, readily offering flexibility to smooth my path. Simple words of encouragement from several consultants have strengthened my determination. On qualifying last year, I felt that I could see light at the end of the tunnel. As a working member of the medical team, I am in a better position to manipulate situations to maximise my hearing. Nevertheless I realise my limitations and still need to work hard to compensate for them.

\section{Working at hearing and understanding}

In the nine years since I (RS) left medical school, I have worked in a variety of busy junior posts in both 